\title{
On Different Tracks? Gender, Professional Strategies, and Early Career Wage Gaps
}

\section{Anne Grönlund'}

Professor, Umeå University, Department of Social Work, Sweden

\begin{abstract}
A longstanding notion in labor market theory is that women accommodate family responsibilities in their occupational and job choices. Utilizing a survey of newly graduated highly educated men and women in five occupations in Sweden ( $n \approx 2400$ ), the article explores whether men and women differ in their professional strategies and if such differences produce early career wage gaps. Findings based on OLS regressions show that women express dual commitment to work and family; compared with men, they value 'family-friendly' work-conditions higher but do not value wages and career lower. Parenthood is not related to lower levels of career focus, but neutralizes occupational differences in family focus for women. Despite the select sample, women have lower wages than men, but the wage gap is not explained by different prioritization of family/career. The findings suggest that assumptions about gendered skill investments must be empirically scrutinized and theories further developed.
\end{abstract}

\section{KEYWORDS}

Career focus / family focus / gender / gender wage gap / human capital / labor market inequality / preference / occupational choice / professional strategy / work-family

DOI

To be announced

\section{Introduction}

ver the decades, research on labor market gender inequalities has rested heavily on Gary Becker's (1985, 1981/1991) notion that women - but not men - accommodate future family responsibilities in their human capital investment strategies, choosing jobs that require less skill development, less time commitment, and less effort than men's jobs, thereby compromising their wage and career prospects. The article utilizes a survey designed to explore the pertinence of such assumptions in the modern, dual-earner context. The aim of the analysis is to examine if men are more career oriented and women are more family oriented in their occupational choices and job search aspirations, if gender patterns vary with the gender composition of the occupation, and, finally, if differences in career/family orientation produce gender wage gaps at an early stage of the career.

Already in 1985, the persistence of gender wage gaps in the face of increased female labor force participation was declared by Becker himself 'an embarrassment to the human capital interpretation of sexual differentials' (1985: S35). Thirty years later, wage differentials appear even more puzzling, as women outnumber men at the

$\overline{{ }^{1} \text { Corresponding author: E-mail: Anne.Gronlund@umu.se. }}$ 
universities in most OECD countries (OECD, 2014a). However, several researchers retain the notion of gendered skill investments, arguing that women's choice of educational and occupational tracks reflect their quest for 'family-friendly' work (e.g., Estevez-Abe, 2006; Polachek, 1981, 2004).

The aim of this article is to put the notion of gendered skill investment strategies to a strong test that could help us assess the contemporary relevance of prevailing theoretical assumptions. The analysis draws on a new dataset comprising Swedish men and women who recently graduated from five higher educational programs, leading to occupations with different gender composition. The sample was stratified such that an equal number of men and women were sampled from each occupation. The intention of the sampling strategy was to expose the impact of individual gender by comparing men and women who are similar in terms of occupation, cohort, and career stage and who live in a context where the gender equal dual-earner family is supported by policies and norms.

\section{Previous research and contribution}

For decades, human capital theory has dominated research on gender, skill investments, and wages. A prominent idea in this theory is that men and women make 'sector-specific' human capital investments: while men maximize their investments in the labor market, women's investments are compromised by their family responsibilities, which are regarded as investments in the human capital of children and spouses (Becker, 1981/1991). More specifically, Becker (1981/1991) claims that women invest less in skill acquisition through schooling and workplace training because families benefit economically from within-couple specialization. Theoretically, the relative productivity of the spouses determines who invests more time and effort in either sphere, but since Becker assumes that men have a higher productivity in the labor market, the prediction is rather straightforward. ${ }^{1}$

The hypothesis seems outdated at a time when the educational investments of women generally exceed those of men, while gender wage gaps persist. Clearly, these wage gaps - also reported from welfare states promoting dual-earner families and gender equality, such as Sweden - are not sufficiently explained by traditional human capital factors. In fact, recent studies report that women's relative wages are particularly low among high-educated employees and in skilled occupations - that is, among groups that are presumably strongly committed to their work and careers (Evertsson et al., 2009; Magnusson, 2010; cf. Albrecht et al., 2003).

However, Becker's argument may still be valid, as skill investments can be gendered in ways not readily captured by traditional human capital variables, that is, years of education and work experience. Occupational gender segregation remains a prominent feature of OECD labor markets (Charles \& Grusky, 2004), and even at the university level, women tend to choose different educational fields than men. Several scholars argue that women's occupational choices are in fact based on anticipations of future family responsibilities. Becker (1985) himself has maintained that because childcare and housework demand a lot of energy, women will economize on their use of energy by choosing occupations and jobs that require less 'effort', that is, jobs that are 'more convenient and less energy-intensive' (ibid 554), in short: 'less demanding jobs' (ibid 555). Building on Becker's 
theory, researchers argue that women, who expect to make work interruptions to care for children, will avoid jobs and occupations that require continuous skill development and such deliberations are presented as a driver behind occupational gender segregation and gender wage gaps (e.g., Estevez-Abe, 2005, 2006; Polachek 1981, 2004). In a similar vein, other scholars argue that women make trade-offs as they choose jobs and occupations with lower wages because they prioritize flexible, 'family-friendly' work arrangements (e.g., Glauber, 2011; Goldin, 2014; McCrate, 2005). In sum, gender differences in professional strategies are invoked to explain inequalities in the labor market including occupational segregation and gender wage gaps.

However, even when occupational tracks are considered, the assumption of gendered investment strategies appears problematic. First, it can be noted that although labor market gender segregation appears rather stable at the aggregate level, several occupations undergo rapid changes in their gender mix, and interestingly, it is primarily in prestigious previously male-dominated occupations requiring higher education that women have gained ground (e.g., England, 2010; Gatta \& Roos, 2005). Second, evidence regarding the 'family-friendliness' of women's jobs and occupations is far from clear-cut: while some studies suggest that the demands for on-the-job training and for time-consuming work can be lower (Grönlund, 2012; Magnusson \& Nermo, 2016), many researchers agree that women's jobs do not involve more schedule flexibility or require less effort in terms of workload (e.g, Goldin, 2011; Lyness et al., 2012). Finally, the idea that the gendered division of work within the family, and the resulting income differences, represents a rational specialization aimed at maximizing household utility has been challenged on several grounds (e.g., Lundberg \& Pollack, 1996; Sørensen \& McLanahan, 1987). Specifically, Iversen and Rosenbluth (2010: page ix) note that, at a time when family dissolution is ubiquitous, 'the image of the family as a welfaremaximizing unit loses contact with reality' because 'having invested all your time and talents in the family is an obvious disadvantage when the family dissolves'. In sum, there are many reasons to believe that, in the modern society, women's motivations for occupational and job choices are more complex than theoretically assumed.

Nevertheless, the notion of gendered work-family strategies is replicated even in recent theories, notably in Cathrine Hakim's $(2000,2002)$ preference theory. Emphasizing the role of lifestyle preferences and values, Hakim claims to provide 'a new explanation for labor market participation and outcomes, especially for women' (Hakim, 2000:430). She argues that attitudes have 'an especially strong impact on women's behavior because women have genuine choices to make regarding employment versus home-making' (Hakim, 2002: 432). As these 'genuine choices' - resulting from a range of societal changes - open up to women in rich modern societies, Hakim expects preferences to become more predictive for labor market outcomes. Presently, she sees Britain and the United States as the prime examples of societies that have entered the new stage of relatively unconstrained choice, and with empirical evidence from these countries, she finds that women can be divided into three groups. A minority of women are either 'home-centered' or 'work-centered', while the largest group comprises 'adaptive' women who combine work and family without giving a fixed priority to either. Instead, they change their priorities over the lifecycle and respond to opportunities and constraints, such as those embedded in social policy. Further, she finds preference categories to be related to gendered employment patterns, such as women's rate of full-time work (ibid). 
Hakim's theory has received substantial criticism, mainly because it implies that women's labor market choices are more or less unconstrained (e.g., Crompton \& Harris, 1998; Crompton \& Lyonette, 2005). The suggested order of causality has been contested by researchers who argue that the relationship between aspirations and behavior can be reciprocal and that both are shaped by structural constraints (Nilsson et al., 2016; McRae, 2003). Longitudinal studies directly testing the tenets of preference theory are rare, but recently, Nilsson et al. (2016) used Swedish longitudinal data to assess preferences for work and family and corresponding outcomes for both genders at ages 21 and 30. The study found that at age 21, women displayed stronger preferences for children than men. At the same time however, they were also more work-oriented than men. Moreover, preferences for work and family at age 21 did not relate to work and family behavior at age 30 for either gender. Finally, the researchers found that parenthood reduced preferences for work among both men and women (cf. Evertsson, 2012).

In sum, central labor market theories depict women's family-orientated skill investments as a main mechanism for labor market gender inequality. Considering the dramatic changes in women's labor force attachment and educational attainments as well as major shifts in gender role attitudes and family stability, such assumptions appear increasingly problematic. The study presented below was designed to explore the links between gender, professional strategies, occupational choice, and wages in a sample that puts the theoretical assumptions to a strong test.

The study is set in Sweden, a country known for its well-entrenched policies promoting gender equality and dual-earner families (e.g., Korpi, 2000; Korpi et al., 2013; Thevenon, 2011). As a result of these policies, which date back to the early 1970 s, female and maternal labor force participation have been high by international standards. In 2015 , the gender gap in employment was less than $4 \%$ in Sweden, as compared with $17 \%$ for the OECD on average (OECD, 2017). Moreover, in Sweden, about $80 \%$ of mothers with children under 3 were employed, as compared with about 52\% in the OECD (as of 2010, OECD, 2014b). The dual-earner/dual-carer family is also evident as a widespread social norm (Edlund \& Öun, 2016). In sum, Sweden provides a context where both policies and norms encourage men and women to combine dual paid work and family throughout the childrearing years and to share the burdens equally. At the same time, Swedish women still take the lion's share of household chores and the care of children (Boye \& Evertsson, 2015) and face persistent disadvantages in the labor market, many of which can be related to occupational gender segregation (e.g., Grönlund \& Magnusson, 2013; Magnusson, 2013). Considering these complexities, Sweden provides an excellent case for examining the extent to which traditional assumptions about gendered investment strategies are relevant for understanding present-day gender inequalities.

The questionnaire was distributed to Swedish men and women that recently graduated from five higher educational programs (engineering, law, psychology, social work, and the police program). The motivation for choosing these programs was to obtain a close-up picture of gender and occupational choice. First, the programs are similar in the sense that they all lead to a specific professional title. Thus, in contrast to more general academic programs, individuals applying for these programs have already made an occupational choice. Second, the programs display clear differences in their gender-mix: two are male-dominated, two female-dominated, and one is gender balanced. Finally, an equal number of men and women were sampled from each educational program (see Data and method).

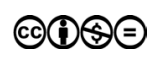


In sum, the design of the study is based on the presumption that if the expected relationships between gender, occupation, strategies, and wages appear in this sample, gendered skill investment strategies may be regarded as a valid and important mechanism for gender inequality even in modern, dual-earner societies.

\section{Aim and hypotheses}

The aim of the article is to examine, first, whether women are less career oriented and more family oriented than men in their motivations for occupational choice and their job search aspirations, second, if gender patterns vary with the gender composition of the occupation, and, third, whether differences in career/family orientation produce gender wage gaps already at the onset of the career.

Based on the theoretical assumptions described above, I propose the following hypotheses:

H1. In their professional strategies, that is, their motivations for occupational/job choices, women in the occupations under study report a higher level of family orientation and a lower level of career orientation than men working in the same occupation.

H2. Strategies are related to occupational gender composition such that individuals in the female-dominated occupations are more family oriented while individuals in the male-dominated occupations are more career oriented. Alternative hypothesis: According to the theoretical assumptions, this impact of occupation applies mainly to women.

H3. Because the presence of children increases the need for within-household specialization, gender differences in strategies increase after controlling for parenthood.

H4. Due to their more family-oriented and less career-oriented strategies, women receive lower wages than men even early in the career.

\section{Data and method}

The questionnaire was distributed in 2013 to Swedish men and women who had graduated from five higher educational programs: Degree of Master of Science in Engineering (hereafter: engineers), Degree of Master of Laws (lawyers), Degree of Master of Science in Psychology (psychologists), Degree of Bachelor of Science in Social Work (social workers), and the Police Program (police officers). The first four programs are all university-based but differ somewhat in length (engineers and psychologists 5 years; lawyers 4.5 years; social workers 3.5 years). The engineering program has several specializations and the sample was drawn from the five largest of these. The Police Program is a post-secondary education provided by the Swedish National Police Academy. The program comprises 1.5 years of studies, but the basic training for police officers also includes 6 months of trainee service.

As mentioned, the programs were chosen because they lead to certain occupations and because these occupations differ in their gender-mix. According to the Swedish 
occupational register, women constitute $26 \%$ of police officers, $20 \%$ of civil engineers, $50 \%$ of lawyers, $72 \%$ of psychologists, and $84 \%$ of social workers in the Swedish labor force aged 16-64 (as of year 2010). Thus, two occupations can be classified as maledominated, two as female-dominated, and one as gender-mixed. Among the individuals graduating from the programs in the academic years 2007/2008-2009/2010, the percentages of women were similar to those in the labor force, but also reflect the trend toward more women in tertiary education.

Furthermore, the sample was stratified such that 500 men and 500 women were sampled from each educational program. In other words, women and men that have made gender-atypical occupational choices have been oversampled so as to minimize the influence of factors other than gender. The stratification also implies that the variable occupation reflects central characteristics of the occupation (e.g., skill requirements) rather than its gender composition. However, to give the reader a more complete understanding of the results, I will also present regressions which use weights that adjust for the oversampling of individuals in gender-atypical occupations as well as for differences in nonresponse across the different strata. Thus, in the weighted regressions, the share of men and women in each occupation corresponds to actual share in the population.

The sample was drawn from the National Register of Higher Education and The Swedish Register of Education and comprised individuals who had obtained a degree from the programs in the years 2007-2010. The timespan was necessary in order to obtain a large enough sample of the underrepresented gender in all educational programs. Sampling, distribution, and coding was administered by Statistics Sweden. The response rate was $55 \%$. In this article, we use a subsample comprising employed individuals who work more than 15 hours a week in the occupation they were trained for $(\mathrm{n} \approx 2400)$.

The empirical analysis comprises two parts. The first part concerns professional strategies, specifically the aspects of career and family orientation.

To capture professional strategies, I utilized seven statements concerning the respondent's motivation for his/her occupational choice and his/her aspirations in the job search process after graduation from the university. For each statement, the respondent was asked to indicate how important that particular aspect had been for him/her (four response alternatives, from 'not important at all' to 'very important'). In a principal component analysis of the response patterns, two separate factors or dimensions were extracted: one factor characterized by high scores for items related to wages and career prospects and another factor with high scores for statements related to work-family reconciliation (see Table Ax1, Appendix). Based on this analysis, I constructed two additive indexes labeled career orientation and family orientation. Career orientation comprises four statements: good initial wages in occupation; ditto in job; possibilities for career advancement and/or good wage development in occupation; ditto for job (range 4-16). Family orientation comprises three statements: the occupation provides work hours that can be adapted to family/partner/private life; ditto for job; the job does not require moving or long-distance commuting (range 3-12). The higher the value, the more important are these aspects.

It is notable that the principal component analysis points to career- and family orientations as two separate dimensions rather than opposite poles on a one-dimensional scale. This allows for a more complex analysis of the relative importance of work and 
family than research on work commitment focusing only on the centrality of the work role (e.g., Evertsson 2012) (see Discussion). A potential drawback of the measure used here is the retrospective nature of the questions, as individuals may have problems of recalling their actions and motivations. However, because educational choice and the job search following graduation are central matters in a young person's life and because the survey was answered a relatively short time after graduation, the problems of recollection should be comparatively small in this sample. Also, the fact that the principal component analysis distinguishes between career and family goals but not between occupational choices and job search aspirations suggests that there is some consistency in motivations over time, although this issue cannot be further explored with crosssectional data.

In the first part of the analysis, the two indicators are used as dependent variables in linear (OLS) regressions aimed at examining whether men and women differ in their professional strategies (H1), if women's strategies are related to the gender composition of the occupation (H2), and if gender differences in strategies increase with parenthood (H3).

The second part focusses on gender differences in wages and the importance of strategies (H4). Stepwise OLS regressions are carried out, using logged monthly wages as the dependent variable. The first model focusses on the effect of gender, controlling for occupation and year of graduation. To examine whether strategies explain the gender effect, career orientation and family orientation are entered in model 2, while model 3 adds the controls of work experience, working time, public/private sector employment, and parenthood.

Descriptive statistics, displayed in Table Ax2, Appendix, show that, despite the sampling strategy of maximum similarity, some gender differences within the occupations can be discerned. Mean work hours are very similar, although there is a significant gender difference among lawyers. Women tend to have shorter work experience, possibly reflecting their longer parental leaves, but the difference is not significant in all groups. Also, even compared to men in the same occupation, women work less often in the private sector. Regarding professional strategies, patterns vary both with gender and occupation. Among civil engineers and police officers, women are more career oriented than men. However, they do not seem to be more family-oriented. Among lawyers, psychologists, and social workers, women are significantly more family oriented than men; however, they are not less career oriented. Finally, we note that women's mean wages are significantly lower among lawyers, psychologists, and social workers, while in the two male-dominated occupations, there is no statistically significant gender wage gap.

\section{Results}

The question of gendered professional strategies - that is, if men are more career oriented and women more family oriented in their occupational choices and their job search aspirations - is addressed in Table 1. For ease of interpretation, I use effect coding, which means that the sum of variable values for each independent variable is zero. Therefore, the intercept can be understood as the average value in the dependent variable across the categorical independent variables. 
Table I Professional strategies, gender, occupation, and parenthood: OLS regressions

\begin{tabular}{|c|c|c|c|c|c|c|c|c|}
\hline & \multicolumn{4}{|c|}{ Career orientation } & \multicolumn{4}{|c|}{ Family orientation } \\
\hline & \multicolumn{2}{|c|}{ Model AI } & \multicolumn{2}{|c|}{ Model A2 } & \multicolumn{2}{|c|}{ Model B I } & \multicolumn{2}{|c|}{ Model B2 } \\
\hline & $\mathrm{b}$ & $\mathrm{se}$ & $\mathrm{b}$ & $\mathrm{se}$ & $\mathrm{B}$ & $\mathrm{se}$ & $\mathrm{b}$ & $\mathrm{se}$ \\
\hline Intercept & 11.22 & 0.05 & 11.22 & 0.05 & 8.86 & 0.04 & 8.92 & 0.04 \\
\hline Man & -0.10 & 0.05 & -0.10 & 0.05 & -0.26 & 0.04 & -0.27 & 0.04 \\
\hline Woman & 0.10 & 0.05 & 0.10 & 0.05 & 0.26 & 0.04 & 0.27 & 0.04 \\
\hline Civil engineer & 1.53 & 0.10 & 1.53 & 0.10 & -0.31 & 0.08 & -0.12 & 0.08 \\
\hline Police officer & -1.50 & 0.10 & -1.50 & 0.10 & -0.07 & 0.08 & -0.10 & 0.08 \\
\hline Lawyer & 1.17 & 0.10 & 1.16 & 0.10 & -0.26 & 0.08 & -0.11 & 0.08 \\
\hline Psychologist & -0.05 & 0.09 & -0.05 & 0.09 & 0.36 & 0.08 & 0.15 & 0.07 \\
\hline Social worker & -1.14 & 0.09 & -1.14 & 0.09 & 0.29 & 0.08 & 0.18 & 0.08 \\
\hline Not parent & & & 0.01 & 0.05 & & & -0.58 & 0.04 \\
\hline Parent & & & -0.01 & 0.05 & & & 0.58 & 0.04 \\
\hline R2 (\%) & 21.5 & & 21.4 & & 3.8 & & 12.0 & \\
\hline$n$ & 2326 & & 2326 & & 2350 & & 2350 & \\
\hline
\end{tabular}

Note: Cell entries are unstandardized regression coefficients (b) and standard errors (se).

Bold coefficients $=$ significantly different from zero $(p<0.05)$.

Contrary to expectations in $\mathrm{H} 1$, the regressions show that, in this sample, women display significantly higher scores on both indices (Table 1, models A1 and B1). These findings do not support the theoretical assumption in human capital theory, which emphasizes gender specialization across the spheres of work and family. Instead, the results suggest that women in this sample - that is, highly educated younger women in a dual-earner context - expect to combine career and family and aim to adapt work demands to family needs without sacrificing their wage- and career development.

To put these findings in a broader perspective, we can compare them with results from weighted regressions, which reflect the actual gender composition in the population, that is, among all individuals graduating from these programs 2007-2010. In weighed regressions, (Table Ax1, Appendix), the level of career orientation is significantly lower for women than for men. Also, the gender difference in family orientation is larger in weighed regressions than in the stratified sample. Thus, both career and family orientations are related to the choice of occupation. However, while gender patterns in career orientation are mediated by occupational choice, traditional gender patterns in family orientation remain in the stratified sample.

Hypothesis 2 states that strategies - particularly women's strategies - should vary systematically with the gender composition of the occupation. Regarding the impact of occupation, weighted regressions (Table Ax4, Appendix) show that the level of career orientation does not vary systematically between the male- and the female-dominated occupations. Instead, career orientation is higher among lawyers and civil engineers than among psychologists, social workers, and police officers. Family orientation appears to be more clearly connected to the gender composition of the occupations, as the level is 
significantly higher among psychologists and social workers and lower among civil engineers and lawyers. For police officers, the coefficient is negative, bordering on statistical significance. These occupational patterns also emerge in the stratified sample and this finding demonstrates that the higher level of family orientation in the female-dominated occupations is more than a simple reflection of individual gender (Table 1, model B1). The fact that the patterns remain after stratification further suggests that individuals both men and women - working in 'gender-atypical' occupations are 'gender-atypical' also in the sense that their professional strategies resemble those of the opposite sex.

Hypothesis 3 states that gender differences in strategies would increase after controlling for parenthood. As displayed in Table 1, model A2, parenthood is not significantly associated with the level of career orientation, but significantly increases the level of family orientation (model B2). The gender difference in family orientation increases slightly when parenthood is taken into account. However, further analysis including an interaction term (not displayed) shows that the overall effect of parenthood does not vary by gender. The table also indicates that occupational patterns in family orientation may be modified by parenthood.

To examine more closely how professional strategies are related to occupational choice and parenthood for men and women, gender-separate regressions were conducted. The results are presented in Table 2.

As summarized in Table 2, the level of career orientation does not vary systematically with the gender composition of the occupations, neither for men nor for women (model A1). Career orientation is significantly higher among civil engineers and lawyers. However, a significant negative effect is found for both social workers and police officers and for psychologists the coefficient is nonsignificant. Further, it can be noted that parenthood (model A2) does not affect the occupational coefficients for either men or women. Thus, in this sample, parenthood does not seem to lower women's career ambitions.

The level of family orientation is more closely related to the gender composition of the occupations (model B1). For both men and women, the coefficients for psychologists and social workers are positive and significantly different from zero, that is, the mean level of the occupations. Female civil engineers and male lawyers also display significant negative effects, while the coefficients for female police officers and male civil engineers are only borderline significant.

Gendered patterns emerge more clearly after accounting for parenthood. As noted above, men in the female-dominated occupations score higher on family orientation than men in the other occupations, especially lawyers. Entering parenthood, in model B2, coefficients are reduced for all occupations; however, they remain statistically significant. In other words, the work context rather than parenthood seems decisive for men's interest in 'family-friendly' work. For women, as a contrast, there is no longer any significant difference between the occupations after controlling for parenthood. Here, we should keep in mind that in the previous model, the coefficients for social workers and psychologists were positive while those for civil engineers and police officers were negative and significant or, in the case of police officers, borderline significant. Thus, it seems that female engineers do not prioritize 'family-friendly' work until they become mothers. A similar pattern can be discerned for police officers, while for female lawyers, the coefficient was nonsignificant and close to zero already in the first model. Taken together, the findings suggest that the impact of parenthood neutralizes the occupational difference for women but not for men. 
Table 2 Differences in professional strategies across five occupations by gender: OLS regressions

\begin{tabular}{|c|c|c|c|c|c|c|c|c|}
\hline & \multicolumn{4}{|c|}{ Career orientation } & \multicolumn{4}{|c|}{ Family orientation } \\
\hline & \multicolumn{2}{|c|}{ Model A I } & \multicolumn{2}{|c|}{ Model A2 } & \multicolumn{2}{|c|}{ Model B I } & \multicolumn{2}{|c|}{ Model B2 } \\
\hline & $b$ & se & $b$ & se & B & se & $b$ & se \\
\hline \multicolumn{9}{|l|}{ MEN } \\
\hline Intercept & 11.12 & 0.07 & II.II & 0.07 & 8.59 & 0.06 & 8.64 & 0.06 \\
\hline Civil engineer & 1.39 & 0.14 & 1.37 & 0.15 & -0.21 & 0.12 & -0.05 & 0.12 \\
\hline Police officer & -1.48 & 0.14 & -1.46 & 0.14 & 0.08 & 0.12 & -0.01 & 0.12 \\
\hline Lawyer & 1.23 & 0.14 & 1.21 & 0.15 & -0.53 & 0.12 & -0.39 & 0.12 \\
\hline Psychologist & -0.13 & 0.13 & -0.11 & 0.14 & 0.40 & 0.11 & 0.22 & 0.11 \\
\hline Social worker & $-\mid .01$ & 0.14 & -1.01 & 0.14 & 0.26 & 0.11 & 0.23 & 0.11 \\
\hline Not parent & & & 0.07 & 0.07 & & & $-0.5 I$ & 0.06 \\
\hline Parent & & & -0.07 & 0.07 & & & $0.5 \mathrm{I}$ & 0.06 \\
\hline R2 (\%) & 19.6 & & 19.7 & & 3.0 & & 9.5 & \\
\hline N & | 057 & & | 057 & & | 067 & & | 067 & \\
\hline \multicolumn{9}{|l|}{ WOMEN } \\
\hline Intercept & 11.32 & 0.06 & 11.33 & 0.06 & 9.13 & 0.05 & 9.21 & 0.05 \\
\hline Civil engineer & 1.64 & 0.13 & 1.66 & 0.13 & -0.38 & 0.11 & -0.17 & 0.10 \\
\hline Police officer & -1.53 & 0.13 & -1.52 & 0.131 & -0.20 & 0.11 & -0.17 & 0.10 \\
\hline Lawyer & 1.12 & 0.13 & 1.14 & 0.13 & -0.04 & 0.11 & 0.13 & 0.10 \\
\hline Psychologist & 0.01 & 0.12 & 0.00 & 0.12 & 0.32 & 0.10 & 0.09 & 0.10 \\
\hline Social worker & -1.25 & 0.13 & -1.27 & 0.13 & 0.25 & 0.11 & 0.12 & 0.10 \\
\hline Not parent & & & 0.05 & 0.07 & & & -0.64 & 0.05 \\
\hline Parent & & & -0.05 & 0.07 & & & 0.64 & 0.05 \\
\hline R2 (\%) & 22.6 & & 22.9 & & 2.1 & & 12.0 & \\
\hline$n$ & 1269 & & 269 & & | 283 & & | 283 & \\
\hline
\end{tabular}

Note: See Table I.

In sum, the analysis shows that women in this sample are not only more family oriented but also more career oriented than men. Thus, H1 is only partly supported. However, the finding is partly related to the stratification of the sample, that is, to the oversampling of the minority gender in each occupation. If the sample would reflect the actual gender composition of the occupations, we would find a traditional gender pattern also regarding career orientation. Thus, occupational choice is more pertinent to the measure of career orientation. The analysis also suggests that individuals in 'genderatypical' occupations are 'gender atypical' in their level of family orientation. This is in line with the claims of $\mathrm{H} 2$. Still, the finding appears to contrast with traditional theoretical assumptions since both human capital theory and preference theory argue that it is 
Table 3 Logged monthly wages:The importance of gender, occupation, and professional strategies; OLS regressions

\begin{tabular}{|c|c|c|c|c|c|c|}
\hline & \multicolumn{2}{|c|}{ Model I' } & \multicolumn{2}{|c|}{ Model 2' } & \multicolumn{2}{|c|}{ Model $3^{1,2}$} \\
\hline & $b$ & se & B & se & $b$ & se \\
\hline Intercept & 9.84 & 0.00 & 9.84 & 0.03 & 9.91 & 0.03 \\
\hline Man & 0.02 & 0.00 & 0.02 & 0.00 & 0.01 & 0.00 \\
\hline Woman & -0.02 & 0.00 & -0.02 & 0.00 & -0.01 & 0.00 \\
\hline Civil engineer & 0.17 & 0.01 & 0.15 & 0.01 & 0.09 & 0.01 \\
\hline Police & -0.25 & 0.01 & -0.24 & 0.01 & -0.20 & 0.01 \\
\hline Lawyer & 0.10 & 0.01 & 0.09 & 0.01 & 0.08 & 0.01 \\
\hline Psychologist & 0.09 & 0.01 & 0.09 & 0.01 & 0.10 & 0.01 \\
\hline Social worker & -0.11 & 0.01 & $-0 . \S 0$ & 0.01 & -0.07 & 0.01 \\
\hline Career orientation & & & 0.01 & 0.00 & 0.01 & 0.00 \\
\hline Family orientation & & & -0.01 & 0.00 & -0.01 & 0.00 \\
\hline R2 (\%) & 60.7 & & 62.0 & & 64.6 & \\
\hline $\mathrm{n}$ & 2213 & & 2213 & & 2213 & \\
\hline
\end{tabular}

Note: See Table I.

' Controlling for year of graduation, work experience, and work hours in all models.

2 Model 3: Controlling for parenthood and public/private sector.

primarily women who adapt their strategies to family demands. $\mathrm{H} 3$ receives no clear support. Parenthood does not explain any of the gender difference in strategies and the overall effect of parenthood does not vary between men and women. Nevertheless, parenthood has a gendered effect in the sense that it neutralizes the occupational differences in family orientation for women, but not for men.

Next, we turn to the issue of wages. H4 stated that women would have lower wages than men. Additionally, the hypothesis argued that this gap would be explained by gendered patterns in professional strategies. Findings from wage regressions are displayed in Table 3.

As seen in Table 3, model 1, there is indeed a significant gender gap in wages after controlling for occupation, year of graduation, work experience, and work hours. In a logged model, the regression coefficient could be interpreted as per cent, thus the difference in monthly wages between men and women in this stratified sample would amount to about $4 \%$. Had the sample not been stratified, the difference would be about $8 \%$, judging by the weighted regressions that adjust for the oversampling of individuals in the gender-atypical occupations (Table Ax3, Appendix).

Returning to Table 3, model 2, we find that career orientation has a positive and significant effect on wages, while the coefficient for family orientation is negative and also statistically significant. Nevertheless, the gender wage gap remains stable after controlling for professional strategies. Thus, the predictions about the impact of strategies are not confirmed. It can be argued that the impact of strategies on gender differences 
would run through work experience and work hours that were controlled for in model 1 ; however, further analysis shows that this is not the case. The same is true for parenthood and public/private sector employment. Entering these variables in model 3, the gender wage gap is reduced from $4 \%$ to $2 \%$ but remains statistically significant. As expected, the coefficient for private sector employment is significant and positive, even when occupation is controlled for. Parenthood has a positive effect on wages, but further analysis shows that the coefficient only becomes statistically significant after strategies are controlled for. Regressions with interaction terms reveal that the positive wage effect of career-oriented strategies is significantly smaller for parents; however, this parenthood effect applies to men and women alike.

Finally, it can be noted that the coefficients for career- and family orientations remain stable and significant through to the final model. In sum, the analysis shows that the gender wage gap is not explained by professional strategies, either directly or indirectly through different choices regarding work interruptions, work hours, or employment sector. A career-oriented strategy is less rewarded for parents, but no gender difference can be discerned in this respect.

In sum, H4 is supported regarding the gender wage gap but not regarding the mechanisms. Even in this select sample of high-educated individuals at an early career stage, women have significantly lower wages than men and the measures of professional strategies do not explain any of the gender wage gap.

To shed further light on the issue, separate wage regressions were conducted for the five occupations (not displayed). Here, a particularly large wage gap (12\%) was found among lawyers, while psychologists and social workers displayed statistically significant wage gaps of $3-4 \%$. For police officers and civil engineers, the gender wage gap was initially nonsignificant, but for civil engineers, it became significant after controlling for strategies. In the final model, the wage gap was nonsignificant for civil engineers and social workers, while among lawyers, the gap was halved as compared to the first model. Although these results should be interpreted with caution, considering the limited sample from each occupation, it is notable that for psychologists and lawyers a statistically significant wage gap of $3 \%$ and $6 \%$, respectively, remained after controlling for reported professional strategies as well as for central factors generally assumed to reflect such strategies.

\section{Discussion}

Researchers concerned with gender inequalities in wages and careers commonly base their hypotheses on human capital theory. Explicitly or implicitly, then, they sustain the notion of gendered human capital investments developed by Becker (1985, 1981/1991), who stated that women, but not men, make long-term investment strategies with future family responsibilities in mind. Recently, the notion of gendered work-family strategies was revived in Hakims preference theory (Hakim, 2000, 2002), although differences within the female group were also highlighted.

Clearly, gender differences both in family responsibilities and in labor market outcomes are prominent patterns in all OECD countries, including Scandinavia. Also, correlations between these two phenomena are well documented, for example, in the literature on the motherhood wage penalty/fatherhood wage premium (e.g., Bihagen et al., 2014; Gough \& Noonan, 2013).

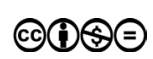


Still, interpretations of the mechanisms behind such findings are not straight-forward, and in the dual-earner society, assumptions of gender-specific strategies seem increasingly problematic. Nevertheless, recent theorizing on labor market gender inequality continues to emphasize women's prioritization of family over career.

The thrust of this paper was to put theoretical assumptions about gendered investment strategies to a strong test. Using a stratified sample of men and women who recently graduated from five higher educational programs in Sweden, I wanted to assess whether the mechanisms suggested in established labor market theories are relevant for understanding present-day labor market inequalities. The aim was to examine if women were less career oriented and more family oriented than men in terms of occupational choices and job search aspirations, if gender patterns varied with the gender composition of the occupation, and, finally, if such differences produced a gender wage gap already at the outset of the career.

The empirical analysis does point to gender differences in professional strategies, but these differences are considerably more complex than theories assume. Compared to men, women in this sample tend to be more family oriented, emphasizing 'familyfriendly' work conditions as important for their occupational choices and in the work search process. At the same time, they do not value wages or career lower than men as suggested by Becker's notion of specialized human capital investments. It could be noted that the stratified sample by definition involves a risk of selection effects, as the minority gender in an occupation may have 'gender-atypical' characteristics. Presumably, however, such effects are likely to be minimized when both men in female-dominated occupations and women in male-dominated are oversampled. More importantly, the empirical analysis point to an overall gender pattern, despite occupational variations. The fact that women in the male-dominated occupations are more career oriented but not less family oriented than their male counterparts, while women in the other occupations are more family oriented but not less career oriented than women's professional strategies reflect a dual commitment to work and family, whereas men appear to be more specialized.

Presumably, the strategies of dual commitment reflect the context of Sweden. Sweden provides comprehensive and well-established policies promoting the dual-earner/dualcarer family, and as a result, the rate of female and, particularly, maternal employment is high by international standards. In this context, it seems reasonable that women aim to combine dual roles in work and family. Still, it is striking that even in this sample of high-educated and relatively young individuals, parenthood emerges as more important for women's professional strategies. Although Scandinavian fathers are often depicted as aiming at a new, more involved fatherhood (e.g., Alsarve et al., 2016; Björk Eydal \& Rostgaard, 2015), this ambition is not reflected in their self-reported professional strategies. The analysis above shows that men's interest in 'family-friendly' work is more related to the work context - specifically, working in a female-dominated occupation than to parenthood status. For women, as a contrast, the existence of children is the decisive factor, neutralizing occupational variation in family orientation. Importantly, however, parenthood does not affect women's career orientation.

The finding that parenthood increases women's level of dual commitment represents an extension in relation to previous research focusing on women's and mother's work commitment. Using a one-dimensional scale that captures only the centrality of work, work commitment becomes a relative feature and specialization in either work and family is assumed. Theoretically, this approach is based on the scarcity or role strain hypothesis. 
The basic premise in this hypothesis is that because people have limited time and energy, dual roles in work and family create stressful conflict, and thus, there is strong incentive to make a choice (Goode, 1960). However, this perspective has been challenged by the role expansion hypothesis. According to this hypothesis, which has received increasing attention in work-family research, dual roles in work and family can enhance both performance and wellbeing in both spheres (Barnett \& Hyde, 2001; Sieber, 1974). The choice of perspective clearly makes a difference as to how effects of gender and parenthood are interpreted. For example, Evertsson (2012), using a scale of work centrality, finds that Swedish mother's work commitment decreases (if only temporarily) when they become mothers. As shown in this article, however, work commitment and family commitment are likely to represent two different dimensions and, in order to better understand the complexity of gender in modern society, these dimensions should be considered in tandem.

Regarding wages, the results reveal that even in this select sample, there is a significant gender wage gap. Importantly, however, this wage gap does not result from women trading off occupational attainments and pecuniary rewards to accommodate their family responsibilities. The indicators of professional strategies do not explain any of the gender wage gap. Arguably, this lack of effect suggests that, for women with dual commitments, negative effects of family orientation may be outweighed by positive effects of their career orientation - perhaps because women aim to prove their worth by putting in extra effort. Still, in this analysis, individual strategies do not offset the effect of gender. The findings show that, already at an early career stage, men and women are differently rewarded for the same educational investments and it is reasonable to assume that this gap will widen over time (cf. Boye et al., 2017 who report an average gender wage gap of $17 \%$ in skilled occupations in Sweden for the year 2010). Despite shunning the 'mummy track', then, young professional women may still find themselves on a different, less profitable, career trajectory than men.

All in all, the findings paint a more complex picture of gendered professional strategies than presented in human capital theory. In some sense, the dual commitment strategy reported by women in this study is compatible with the notion of 'adaptive' women, presented in Hakim's preference theory. However, since men and women's career and family orientations vary in similar ways across occupations, men, too, can be described as 'adaptive'. Also, it should be noted that the 'adaptive' group is by far the largest group in the modern dual-earner society (cf. Hakim, 2000). Arguably, then, this group of women - with dual commitment to work and family - merits more attention if contemporary inequalities are to be understood. Finally, and importantly, the results presented here do not support the claims, made by human capital theory and preference theory alike, that gender differences in professional strategies explain gender wage gaps.

Obvious drawbacks of the study are the cross-sectional design and the retrospective questions used to measure strategies. Although it can be argued that the problems of recalling their actions and motivations may not be too large for individuals approached a few years after graduation, no causal inferences can be drawn from cross-sectional data. The stratified sample comprising five occupations enabled a close-up view on men and women with similar endowments working in both gender-typical and gender-atypical occupations, but the findings from this select sample cannot be generalized to the labor market as a whole. To underpin and develop the conclusions in this study, there is not only a need for qualitative studies exploring the existence and nature of gendered professional strategies but also for longitudinal studies examining the relevance of aspirations and strategies for

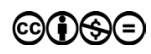


men and women's wage- and career trajectories. Finally, theories need to develop updated understandings of gender, skill investments, and labor market inequality.

\section{Acknowledgment}

For financial support, the author gratefully acknowledges the Swedish Research Council for Health, Working Life and Welfare (FORTE) grant number 2011-0816.

\section{References}

Albrecht, J. W., Björklund A and S. B. Vroman (2003). Is there a glass ceiling in Sweden? Journal of Labor Economics 21(1), 145-177. doi: http://dx.doi.org/10.1086/344126.

Alsarve, J., Boye, K. \& Roman, C. (2016). ‘The crossroads of equality and biology. The child's best interests and constructions of motherhood and fatherhood in Sweden' In Grunow, D. \& Evertsson, M. (Eds.). Couples' Transitions to Parenthood: Analysing Gender and Work in Europe. Edward Elgar Publishing. doi: http://dx.doi.org/10.4337/9781785366000.

Barnett, R. C. and Hyde, J. S. (2001). 'Women, Men, Work, and Family: An Expansionist Theory', American Psychologist 56(10), 781-796. doi: http://dx.doi.org/10.1037/0003066X.56.10.781.

Becker, G. (1985). Human Capital, Effort and the Sexual Division of Labor. Journal of Labor Economics 3(1), 33-58. doi: http://dx.doi.org/10.1086/298075.

Becker, G. S. (1981/1991). A Treatise on the Family. Cambridge, MA: Harvard University Press.

Bihagen E., Nermo M. and Stern L. (2014). The gender gap in the business elite: Stability and change in characteristics of Swedish top wage earners in large private companies, 19932007. Acta Sociologica 57: 119-133. doi: http://dx.doi.org/10.1177/0001699313495422.

Björk Eydal, G. and T. Rostgaard (2015). Fatherhood in the Nordic Welfare States. Comparing care policies and practice. Bristol: Policy Press.

Boye, K. and M. Evertsson (2015). Who does what when? The development of the time spent on housework by women and men in Sweden, SPaDE Working Paper Series 2015: 1.

Boye K., Halldén K., and Magnusson M. (2017). Stagnation only on the surface? The implications of skill and family responsibilities for the gender wage gap in Sweden, 1974-2010. British Journal of Sociology, epub ahead of print, doi: http://dx.doi.org/10.1111/14684446.12252.

Charles M. and Grusky D. B. (eds) (2004). Occupational ghettos. The worldwide segregation of women and men. Stanford, CA: Stanford University Press.

Crompton, R. and F. Harris (1998). Explaining Women's employment Patterns: 'Orientations to Work' Revisited, The British Journal of Sociology 49(1), 118-136. doi: http://dx.doi. org/10.2307/591266.

Crompton, R. and C. Lyonette (2005). The new gender essentialism - domestic and family 'choice' and their relation to attitudes, The British Journal of Sociology 56(4), 601-620. doi: http://dx.doi.org/10.1111/j.1468-4446.2005.00085.x.

Edlund, J. and Öun, I. (2016). Who should work and who should care? Attitudes towards the desirable division of labor between mothers and fathers in five European countries, forthcoming in Acta Sociologica. doi: http://dx.doi.org/10.1177/0001699316631024.

England, P. (2010). 'The gender revolution: Uneven and stalled', Gender and Society 24: 149-166. doi: http://dx.doi.org/10.1177/0891243210361475.

Estévez-Abe M. (2005). Gender bias in skills and social policies: The varieties of capitalism perspectives on sex segregation. Social Politics 12: 180-215. doi: http://dx.doi. org/10.1093/sp/jxi011. 
Estévez-Abe M. (2006). Gendering the varieties of capitalism. A study of occupational segregation by sex in advanced industrial countries. World Politics 59: 142-175. doi: http:// dx.doi.org/10.1353/wp.2007.0016.

Evertsson, M., England, P., Mooi-Reci, I., Hermsen, J., de Bruijn, J. and Cotter, D. (2009). 'Is gender inequality greater at lower or higher educational levels? Common patterns in the Netherlands, Sweden, and the United States', Social Politics 16: 210-241.

Evertsson, M. (2012). The importance of work: Changing work commitment following the transition to motherdhood, Acta Sociologica 56(2), 139-15. doi: http://dx.doi. org/10.1093/sp/jxp008.

Gatta, M., Roos, P., 2005. Rethinking occupational integration. Sociological Forum 20, 369-402. doi: http://dx.doi.org/10.1007/s11206-005-6594-5.

Glauber, R. (2011). Gender, Occupational Composition and Flexible Work Scheduling. The Sociological Quarterly, 52, 472-94.

Goldin, C. (2014). A Grand Gender Convergence: Its Last Chapter. American Economic Review 104(4), 1091-1119. doi: https://doi.org/10.1257/aer.104.4.1091.

Goode, W. J. (1960). ‘A Theory of Role Strain', American Sociological Review 25(4), 483-496. doi: http://dx.doi.org/10.2307/2092933.

Gough M. and Noonan M. (2013). A review of the motherhood wage penalty in the United States. Sociology Compass 7: 328-342. doi: http://dx.doi.org/10.1111/soc4.12031.

Grönlund A. (2012). On-the-job training - a mechanism for segregation? Examining the relationship between gender, occupation and on-the-job investments. European Sociological Review 28(3), 408-420. doi: http://dx.doi.org/10.1093/esr/jcr007.

Grönlund A., Magnusson C. (2013). Devaluation, crowding or skill specificity? Exploring the mechanisms behind the lower wages in female occupations. Social Science Research 42(4), 1006-1017. doi: http://dx.doi.org/10.1016/j.ssresearch.2013.03.001.

Hakim, C. (2000). Work-Lifestyle Choices in the 21st Century. Preference Theory. Oxford: Oxford University Press.

Hakim, C. (2002). Lifestyle Preferences as Determinants of Women's Differentiated Labor Market Careers, Work and occupations 29(4), 428-459. doi: http://dx.doi.org/10.1177/ 0730888402029004003.

Iversen, T. and Rosenbluth, F. (2012). Women, Work and Politics. The Political Economy of Gender Inequality, London: Yale University Press.

Korpi, W., Ferrarrini, T., and Englund, S. (2013). Women's opportunities under different family policy constellations: Gender, class, and inequality tradeoffs in western countries re-examined. Social Politics 20(1), 1-40. doi: http://dx.doi.org/10.1093/sp/jxs028.

Lundberg, S., and Pollak, R. A. (1996). Bargaining and distribution in marriage. The Journal of Economic Perspectives 10(4), 139-158, doi: http://dx.doi.org/10.1257/jep.10.4.139.

Lyness, K. S., Gornick, J. C., Stone. P. and Grotto, A. R. (2012). It's All About Control: Worker Control over Schedule and Hours in Cross-National Context. American Sociological Review 77(6), 1023-1049. doi: http://dx.doi.org/10.1177/0003122412465331.

Magnusson C. (2010). Why is there a gender wage gap according to occupational prestige?: An analysis of the gender wage gap by occupational prestige and family obligations in Sweden. Acta Sociologica 53(2), 99-117. doi: http://dx.doi.org/10.1177/0001699310365627.

Magnusson, C. (2013). More Women, Lower Pay? Occupational sex composition, wages and wage growth. Acta Sociologica, 56, 227-245. doi: http://dx.doi.org/10.1177/ $\underline{0001699313484480 .}$.

Magnusson C. and M. Nermo (2016). Gender, Parenthood and Wage Differences: The Importance of Time-Consuming Job Characteristics, Social Indicators Research, doi: http:// dx.doi.org/10.1007/s11205-016-1271-z.

McCrate, E. (2005). Flexible Hours, Workplace Authority, and Compensating Wage Differentials in the US. Feminist Economics, 11, 11-39. Magnusson C. and M. Nermo (2016). 
Gender, Parenthood and Wage Differences: The Importance of Time-Consuming Job Characteristics, Social Indicators Research, doi: 10.1007/s11205-016-1271-z.

McRae, S. (2003). Constraints and Choices in Mothers' Employment careers: a Consideration of Hakim's Preference Theory, British Journal of Sociology 54(3), 317-338. doi: http://dx.doi.org/10.1111/j.1468-4446.2003.00317.x.

Nilsson, K., Hammarström A. and M. Strandh (2016). The relationship between work and family preferences and behaviors. A longitudinal study of gender differences in Sweden, Acta Sociologica, pre-publication. doi: http://dx.doi.org/10.1177/0001699316659322.

OECD (2014a). Education at a Glance 2014: OECD Indicators, OECD Publishing. doi: http://dx.doi.org/10.1787/eag-2014-en.

OECD (2014b). OECD Family Database. Available at https://www.oecd.org/els/family/database.htm (accessed October 29, 2014).

OECD (2017). OECD Emloyment Database. Labor Force Statistics (accessed April 21, 2017).

Polachek, S. W. (1981). 'Occupational self-selection: A human capital approach to sex differences in occupational structure', The Review of Economics and Statistics 63: 60-69. doi: http://dx.doi.org/10.2307/1924218.

Polachek, S. W. (2004). How the Human Capital Model Explains Why the Gender Wage Gap Narrowed. IZA Discussion Paper No. 1102.

Sieber, S. (1974). 'Toward a Theory of Role Accumulation', American Sociological Review 39(4), 567-578. doi: http://dx.doi.org/10.2307/2094422.

Sørensen, A., and McLanahan, S. (1987). Married women's economic dependency, 1940-1980. American Journal of Sociology, (92), 659-687, doi: http://dx.doi.org/10.1086/228792.

Thévenon, O. (2011). Family policies in OECD countries: A comparative analysis. Population and Development Review, 37(1), 57-87. doi: http://dx.doi.org/10.1111/j.17284457.2011.00390.x.

\section{Note}

${ }^{1}$ The hypothesis has been criticized for drawing on biological gender differences but Becker has argued that discrimination of women, too, would give men a comparative advantage in the labor market and that the initial difference does not have to be large. The point is that specialization is beneficial - and increasingly so over time as it motivates further sector-specific skill investments. 